\title{
OVER DEN KLEINEN LANDBOUW IN SURINAME \\ DOOR
}

J. A. LIEMS

De heer C. van Drimmelen, destijds Agent Generaal der immigratie, die door zijn langdurig verblijf in Suriname en het vervullen van verschillende betrekkingen èn met de bevolking èn met den economischen toestand grondig bekend is, hield op 18 December 1918 voor de R. K. Sociale cursus eene lezing over: een middenstandslandbouw voor Suriname. In deze lezing zegt hij op blz. 21/23: „S u rin a me is vanaf hare grondvesting een , landbouwende kolonie geweest en nog altijd bestaat ruim „50\% harer bevolking van den akkerbouw. De vrucht„bare kuststreek, welke haar ontstaan dankt aan de sa„menwerking van de zee en de rivieren, is als 't ware aan„gewezen voor de bebouwing met tropische voortbreng„selen voor uitvoer. De geschiedenis van den landbouw „kan men daarom zeggen, is tegelijk de economische ge"schiedenis van het land. Het groot landbouwbedrijf in "S u ri n a m e, waaronder verstaan wordt de land„bouw, aanvankelijk gedreven met uit $\mathrm{Afrika}$ aan"gevoerde slaven en na afschaffing der slavernij met uit „A z i e overgevoerde contract-arbeiders - tot voor „vijftig jaren de eenige bedrijfsvorm op dit gebied - heeft "ongetwijfeld tijden van bloei gekend, doch nog veel „meer tijden van depressie en crisis, vaak zelfs van diep „verval....

...., Of de groote landbouw, zooals die in Suriname "gedreven wordt, er ooit weer bovenop komt, is een vraag "waarop het antwoord in een somber duister ligt. Op „zijn best genomen kunnen wij daarvan zeggen: wij ho- 
„pen het, namenlijk, als de arbeiders-immigratie blijft „bestaan en Nederland meer nog dan thans het geval is, „den aanvoer van arbeidskrachten geldelijk blijft steu„nen.

„Komt de groote landbouw er weer bovenop, durven „kapitalisten gelden beschikbaar stellen voor nieuwe on„dernemingen, dan kunnen de zaken in de kolonie daarop „blijven drijven, er zal dan weer meer vertier komen, een „,zeker aantal gezagvoerders en opzichters zullen er een „,bestaan vinden, eenige honderdtallen arbeidskrachten „uit Java zullen worden aangevoerd, maar een welva„rende landbouwende middenstandige klasse van bur„gers, die het meest zou kunnen bijdragen tot de econo„mische en moreele ontwikkeling van de bevolking, voor„al tot een meer duurzame welvaart, zal er zoo min als „,vroeger uit geboren worden; als tak van volksvlijt is "deze kapitalistische bedrijfsvorm ten eenenmale on„bruikbaar."

De heer Van Drimmelen geeft dan verder aan hoe naar zijne meening in deze sociale leemte moet worden voorzien.

De heer S. Beck, ook een alleszins tot oordeelen bevoegd persoon, komt in zijne zes jaren later te Paramaribo gehouden lezingen over "Surinaamsche problemen" tot de volgende uitspraak;

„In ieder geval verdient het de volle aandacht, dat de „landbouw een gebied, men kan gerust zeggen op het „oogenblik het eenige gebied in de kolonie is, dat voor af„zienbaren tijd aan een geheel onbeperkt aantal men„schen een verdienste en een bestaan kan bieden."

Hierop laat hij volgen: „En toch is het noodig, dat wij „ons dat telkens voor oogen stellen, want men zegt het „wel en men spreekt van Suriname als van een landbouw„drijvende kolonie, maar men beseft meestal niet ten „volle dat het hier inderdaad om het Surinaamsch pro„bleem gaat en dat de toekomst der kolonie afhangt van „het hoe en van de wijze waarop de landbouw — ik laat „hier in het midden de groote of de kleine landbouw „tot ontwikkeling gebracht wordt." 
Een ieder zal het er wel mee eens zijn, dat er voor 's hands geen andere oplossing voor het Surinaamsch probleem te vinden is dan in de ontwikkeling van den landbouw. Het komt maar op de wijze van uitoefening aan.

Suriname's bodem is zeer vruchtbaar, daarover zijn alle deskundigen het eens. En toch is de geschiedenis van den grooten landbouw in Suriname veelal een lijdensgeschiedenis, zooals door den heer Van Drimmelen is aangetoond.

De geschiedenis van den kleinen landbouw komt in het kort op het volgende neer. Deze tak van volksvlijt werd eerst na 1873 van beteekenis voor de samenleving, toen al de in 1863 vrijverklaarden volkomen vrijheid van beweging kregen. De besten onder hen vestigden zich op verlaten plantages of op pachtgronden langs de rivieren en legden zich op de cacaocultuur toe. Velen brachten het tot zekeren welstand. Het inpolderen en op loozing brengen van gronden langs de rivier, waar oerbosch op stond was zeer moeilijk en zwaar werk, waartoe niet iedereen in staat was. Elk grondje vormde een poldertje op zich zelf, waarvan de onderhoudskosten niet gering waren. Het Gouvernement richtte daarom meestal op oude plantages, centrale vestigingsplaatsen in. De van hun werkcontract met de plantages vrijkomende Britsch-Indische immigranten en later ook de Javanen, vestigden zich gaarne op deze centrale vestingsplaatsen. Een kleiner deel vestigde zich als vee- en groente boeren in de omstreken van Paramaribo.

Sedert door ziekten in de cacao deze cultuur niet meer loonend is, is ook bij den kleinen landbouw misère troef, wegens gebrek aan een ander product voor uitvoer.

De bodem is rijk, het klimaat voortreffelijk, er bestaat verscheidenheid genoeg in de grondsoorten om vrijwel alle tropische gewassen te telen, maar wij kunnen meestal niet op de wereldmarkt concurreeren. De meening ligt dan voor de hand, dat aan onzen bedrijfsvorm iets hapert. Om te weten waar bij ons de fout zit, moeten wij onderzoeken onder welke omstandigheden de gewassen, waarvoor 


\section{4}

OVER DEN KLEINEN LANDBOUW IN SURINAME

onze bodem en ons klimaat geschikt zijn, in andere landen voor de wereldmarkt geteeld worden.

Wij zien dan, dat in landen met hoogen loonstandaard gebruik gemaakt wordt van handenarbeid-besparende werktuigen, machines en dierlijke kracht. Zelfs in de Aziatische landen met lagen loonstandaard wordt meer gebruik gemaakt van dierlijke kracht en - wel is waar niet zeer moderne - werktuigen dan in Suriname.

En dan rijzen de volgende vragen: Waarom verkeeren wij ten deze nog steeds in het stadium van proefnemingen? Waarom zijn vroeger de ernstige pogingen van mannen als Cabell en van Esveld (de eerste had voor dit doel een flinken Hollandschen boer laten komen) en later van Putscher tot aanwending van deze werktuigen zonder gunstige resultaten gebleven? Waarom gebruiken de $\mathrm{Br}$. Indiers en Javanen de in hun land gebezigde (primitieve) werktuigen hier niet?

De verklaring van dit opmerkelijk verschijnsel, is dat, op de kleigronden, althans, volgens het tot nu gevolgd systeem, het aantal dagen per jaar, waarop door middel van dierlijke trekkracht gebruik gemaakt kan worden van handenarbeid besparende werktuigen, door weersomstandigheden veel te klein is. De besparing van arbeid gedurende een korten tijd weegt niet op tegen den arbeid en de kosten van verzorging der dieren gedurende een veel langeren tijd. De grond op een gegeven tijdstip te vochtig om geploegd te worden, is reeds na 2 à 3 weken te hard. Maar aangenomen dat men gedurende den drogen tijd heeft kunnen ploegen en eggen en met de eerste regens gezaaid, of geplant heeft, dan moet het later opschietende onkruid ook verdelgd kunnen worden. De grond is dan echter reeds vochtig en kleeft aan de werktuigen welke voor onkruidverdelging gebruikt worden.

Men vervalt dan weer tot duren handenarbeid.

Den grond in den voor ploegen vereischten vochtigheidstoestand houden, kan bereikt worden door een goed ingericht irrigatie-systeem. Het probleem van onkruidbestrijding is veel moeilijker, zoo niet onmogelijk, op te lossen. Te veel water maakt de onkruidbestrijding langs 
mechanischen weg onmogelijk. Daarentegen kan het water ons dienen om onkruid te voorkomen, door het land daarmede te overdekken. Daarbij is echter elke andere cultuur dan die van rijst uitgesloten. Maar de cultuur der andere éénjarige gewassen - uitgezonderd suikerriet is niet loonend, omdat het gebruik van werktuigen bij hunne teelt onmogelijk is.

In de „Agricultural Gazette of New South Wales”, No. van December 1924 blz. 856 staat: „,The biggest pest ,,that the ricegrower has to fight is the weedgrowth, and ,,many methods have been adopted to overcome this ,trouble. It is much better to try to prevent weeds than ,,to try to eradicate them from a rice plant. Good farming ,with fallowing tends to keep weeds down, and hand pull,,ing especially along ditches and check banks, can be of ,great assistance. Where rice has been grown for a season ,or two, it is very noticeable that weeds become very ,,bad unless preventive methods be adopted. When it is ,,known that the land is infected with weed seeds, the ,,practice of putting water on to the land so that it ,,becomes covered, and then sowing the seeds into the ,water, has been adopted."

Het onder water zaaien zal in Suriname waarschijnlijk niet toepasselijk zijn; proeven daarmede hadden geen gunstig resultaat.

Het verdelgen van onkruid vóór het planten wordt reeds lang in Nickerie toegepast. Het systeem op Alkmaar - aan de Commewijne rivier - is navolging en tevens verbetering hiervan.

De heer Van Drimmelen in zijne boven reeds aangehaalde lezing zegt over de rijstcultuur sprekende: „Geen „deel van Amerika leent zich beter voor deze cultuur dan „dat, waarin Suriname is gelegen. De rijst kan voor Su„riname worden wat de tarwe is voor Argentinië en "Canada."

Ik neem die uitspraak gaarne over, omdat bij een behoorlijke irrigatie- en drainage-systeem de productieprijs van rijst belangrijk lager kan zijn, dan het cijfer dat de heer Van Drimmelen voor oogen had. Dit is in 1924 
duidelijk gebleken bij eene vrij eenvoudige inrichting als van den rijstpolder achter de vestigingsplaats Alkmaar, waar alleen in den regentijd over bevloeiingswater beschikt wordt. Door het aanleggen van kleine secundaire leidingen rechthoekig op den hoofdaanvoer en het in vakken verdeelen der perceelen kan elk willekeurig vak naar behoefte geïnundeerd of drooggelegd worden. De werkwijze op de aldus ingerichte perceelen verschilt met die op andere plaatsen gevolgd hierin, dat het met den tjap omwerken van den natten grond vermeden wordt. Dit omslaan van den grond (moddermaken) dient om het onkruid tegen te houden, maar is zeer tijdroovend en nadeelig voor de structuur van den grond.

Op Alkmaar laat men elk vak dadelijk onder water loopen zoodra het onkruid er afgeslagen is. Wiedstompen en opslag worden door het water geheel verstikt. Tegen den tijd van planten is de grond volmaakt schoon. Zóó schoon is de grond dan, dat sommigen een deel van hun perceel bezaaien en het ander deel met bibit beplanten. Het goedkoopere zaaien wordt niet op het geheele perceel toegepast, omdat het geplante deel eerder rijpt en het oogsten dus over een langere periode verdeeld wordt. $\mathrm{Na}$ het planten wordt de bodem weer door middel van het bevloeiingswater vrij van onkruid gehouden.

Het omslaan van den grond vereischt evenveel tijd als het afwaaien (neersabelen) van het onkruid en planten van de bibit samen, zoodat met de nu toegepaste werkwijze per hoofd, in een seizoen tweemaal zooveel oppervlakte als vroeger beplant wordt. Dit is op Alkmaar praktisch bewezen.

Algemeen wordt van de rijst gezegd, dat ze een cultuur is voor paupers en dat rijstbouwers het nooit tot welvaart kunnen brengen, omdat de geldswaarde van het product per vlakte-eenheid klein is.

Die stelling is aanvechtbaar. Alleen voor dichtbevolkte landen, waar de grond een groote geldswaarde vertegenwoordigt, gaat ze op. In Italië en Spanje waar de grond zeker wel duurder is dan in Suriname, wordt de rijst in het groot met voordeel geteeld. 
De rentabiliteit van elke onderneming hangt af van het verschil tusschen den productieprijs en dien welke het product op de markt kan bedingen. Bij de op Alkmaar gevolgde, nog voor vele verbeteringen vatbare, werkwijze laat de productieprijs bij een lage markt van de rijst een nog zeer bevredigende winstmarge toe. Volgens opgave van twee der beste landbouwers aldaar, was de productie-prijs in 1924 ongeveer 4 cts per K. G. droge ongepelde rijst. Voor 1925 verwachten zij, dat de prijs lager zal zijn. Ter loops moet er op gewezen worden, dat dit resultaat bereikt is uitsluitend met handenarbeid.

De in Italië b.v. zeer hooge kosten van wieden worden bespaard .In de „Indische Mercuur” van 21 Maart 1924 geeft de heer L. Koch de kosten voor de eigenlijke cultuur op de boerderij Robarello per bouw $(0.7$ H. A.) berekend, als volgt op:

Grondbewerking. . . . . . . . . . . . . $f$ 20.Het in den grond brengen v. d. aanplant . . - 14.16 Wieden. . . . . . . . . . . - 63.-

Oogsten . . . . . . . . . . . . . . . . . . $\frac{-51.05}{f 148.21}$

Eerst bij een behoorlijk ingericht irrigatie- en drainagesysteem zal het bewerken van den grond met moderne werktuigen kans van slagen hebben. Met een behoorlijk irrigatie- en drainage-systeem wordt bedoeld, dat ook in den drogen tijd over voldoend bevloeiingswater beschikt wordt, terwijl men ook van goeden afvoer in den regentijd moet verzekerd zijn.

Het bevloeiingswater zal van een hooger gelegen terrein naar een lager geleid of door oppompen opgevoerd moeten worden.

Bij waarnemingen voor een eventueele doorgraving bij Carel François naar de Coesewijne is gebleken, dat, in den regentijd althans, het niveau van deze rivier hooger ligt dan dat van de Saramacca. Dit verschil in niveau makkt het bevloeien van het land tusschen de beide rivieren op goedkoope wijze mogelijk, terwijl het verval in 
de Saramacca rivier voldoende is voor goede loozing van het terrein. Een polder op het terrein tusschen Carel François en Groningen met inlaat (of inlaten) bij de Coesewijne en uitlaten in de Saramacca is verzekerd van goedkoop bevloeiingswater door middel van een sluis in den regentijd. In den drogen tijd zal het water slechts enkele meters opgepompt moeten worden en dus niet al te duur uitkomen omdat voor de dan te telen gewassen minder water noodig is dan voor de rijst. Er zijn meer terreinen voor het doel geschikt, maar de aandacht wordt op dit terrein gevestigd, omdat het gunstig is gelegen en vrijwel geheel uit domeinland bestaat.

In den hier gedachten polder zal in den regentijd rijst kunnen worden verbouwd tegen een productie-prijs, die aanzienlijk lager zou kunnen zijn dan nu reeds op Alkmaar wordt behaald en waardoor de kans op afzet tegen loonenden prijs op de wereldmarkt mogelijk of beter verzekerd is. Na den rijstoogst zal door middel van het bevloeiingswater de grond in den voor ploegen meest gunstigen toestand kunnen worden gebracht en verder in den voor de andere cultures meest geschikten toestand worden gehouden.

Het onkruid is gedurende de rijstteelt zoo goed als geheel door het water onderdrukt. De grond is dus na den rijstoogst vrij schoon en de rijststoppel kan dadelijk worden ondergeploegd. Daarbij kan het voorbeeld van Italië worden gevolgd en om de 8 meters twee voren van ongeveer $0.25 \mathrm{M}$. diepte worden opengelaten, zoodat men bedden van ongeveer $8 \mathrm{M}$. breedte en greppels van $0.25 \mathrm{M}$. diepte krijgt, wat voor tweede gewassen als maïs en boonen voldoende draineering is in het niet natte seizoen.

In Italië kan men slechts een beperkt deel van het land voor een tweede gewas gebruiken. In de laatste jaren is men daar er toe overgegaan om het overplant-systeem toe te passen. Het overplanten kan twee maanden later dan het zaaien geschieden en hierdoor kan in het voorjaar nog een klaver- of een koolzaadoogst verkregen worden. Het overplanten kan echter slechts over een beperkt 
deel van den aanplant worden toegepast, omdat men in het jaargetijde het noodig werkvolk mist.

In ons geval zal na den rijstoogst verbouw van maïs en boonen over het geheele land en tegen lage productiekosten mogelijk zijn. Andere cultures w. o., vezelstoffen als malachra en dergelijke zullen, met beter gevolg dan vroeger, kunnen worden beproefd, omdat in tegenstelling met den regentijd de bestrijding van onkruid door middel van doelmatige werktuigen mogelijk wordt.

Sommige gewassen zullen dicht gezaaid (of geplant) kunnen worden om al te weelderigen onkruidgroei tegen te gaan en te zijner tijd uitgedund kunnen worden voor eigen veevoer. Bij andere zal een tusschengewas kunnen worden geteeld. In elk geval zal er naar gestreefd moeten worden om den grond steeds zooveel mogelijk beschaduwd te houden, zoowel ter onderdrukking van onkruid als tegen de schadelijke inwerking van directe zonnestralen (o. a. te snelle vertering van de humus) en zwaren regenval (dichtslaan en dichtslibben van den grond).

Tot behoud van een goede structuur van den grond, waar die reeds bestaat en ter verbetering, waar de structuur te wenschen overlaat, zullen de op het land achterblijvende plantendeelen zoo weinig mogelijk afgebrand moeten worden. Ze dienen te worden ondergewerkt, of ten minste op het land moeten blijven verrotten. De zorg voor een voldoend humusgehalte van den kleigrond is - behalve om de voedende bestanddeelen die deze bevat - van zeer veel belang voor zijne bewerkbaarheid. Daarom zal in de vruchtwisseling ook het telen van een groenbemester moeten worden opgenomen.

Dat planten in den drogen tijd evengoed, zelfs beter, gedijen dan in den regentijd als de grond maar voldoende vochtig is, mag als algemeen bekend worden verondersteld. Het vochtig houden van den grond wordt niet alleen door toevoer van bevloeiingswater bereikt, maar ook door het loshouden van den bovengrond, waardoor de verdamping wordt tegengegaan (dry farming). Ook dit kan door middel van werktuigen goedkoop geschieden. Men heeft dan geen of weinig bevloeiingswater noodig. 
De bemesting met andere stoffen dan de op het land achterblijvende plantenresten - behalve eventueel gebruik maken van een groenbemester - kan, als niet urgent, vooreerst buiten bespreking blijven.

Het allereerst noodige is een bedrijfsvorm die ons in staat stelt de gewassen, (vooral eenjarige) waarvoor bodem en klimaat geschikt zijn, te telen tegen concurreerende prijzen.

Het vorenstaande heeft niet de pretentie van de oplossing van het vraagstuk aan te geven, maar moet beschouwd worden als een punt van uitgang uit een der vicieuse cirkels om ons heen. Goedkooper productie gaat hier gepaard met meer productie. Hebben wij veel productie aan te bieden, dan kunnen wij allicht ook lager vrachtprijzen bedingen. Voeren wij meer uit, dan wordt onze betalingsbalans gunstiger en komen wij van den hoogen wisselkoers, die tot de duurte bijdraagt, af. En zoo komt van het een het ander.

Een interessant voorbeeld, hoe de eene verbetering andere met zich meebrengt is het volgende: In 1924 konden, als gevolg van de plaats gehad hebbende malversatie bij de Commewijne Landbouwleenbank, geen voorschotten aan landbouwers worden verstrekt. De enkele landbouwers op Alkmaar, die reeds in 1923 volgens het bovenaangehaalde systeem hadden gewerkt, werden bereid gevonden om door tusschenkomst van den opzichter, tegen matige rente, geld op korten termijn aan anderen te leenen om hen in de gelgenheid te stellen hunne perceelen in te richten. Partijen waren aan elkaar volkomen bekend, zoodat alleen aan betrouwbare personen voorschotten werden verleend. Alle voorschotten werden op tijd terugbetaald. In 1924 bedroeg het op deze wijze uitgeleende bedrag slechts $f$ 400.- Voor 1923 is voor dit doel $f$ 2000.beschikbaar gesteld. Zonder veel theorie of propaganda is op eenvoudige wijze hier het Raiffeisen-systeem in toepassing gebracht.

In zijne lezing zegt de heer Beck- „De oplossing van „het probleem moet dus van twee kanten worden aan,gepakt: 
, $1^{\circ}$. van den economischen kant, dat wil zeggen: Er „moeten bedrijfsvormen gevonden en geschapen wor„den, die aan de bevolking behoorlijke bestaansvoor„waarden bieden en

„2 $2^{\circ}$. van den opvoedkundigen kant."

Het eerste is, van zelf sprekend, het voornaamste, want trots de beste bedrijfsopvoeding, in of buiten internaten, zal de bevolking niet naar den landbouw (het bedrijf waartoe de heer Beck zich in deze lezing bepaalt) worden getrokken als zij er geen behoorlijk bestaan in vindt.

Verder wijst de heer Beck op de noodzakelijkheid, dat alles in het werk dient gesteld te worden, wat er toe kan leiden eene cultuur voor den kleinen landbouw te vinden, waarvan het product in elke hoeveelheid uitgevoerd kan worden. Dit product zal volgens hem de sinaasappel moeten zijn, omdat de bacove om verschillende redenen niet in aanmerking komt en de katoen bepaalde streken vereischt.

Het is echter duidelijk, dat één cultuur niet voldoende bestaanszekerheid kan verschaffen, althans niet aan vrijwel de geheele bevolking. Bovendien, de sinaasappel is een meerjarig gewas, dat niet vóór het $5 \mathrm{e}$ jaar rendabel kan zijn. De cultuur vereischt dus aanlegkapitaal of een zeker uithoudingsvermogen gedurende eenige jaren. De zorgvuldige behandeling, die de vrucht als exportartikel vereischt, maakt deze cultuur voor de onontwikkelde massa ongeschikt. Eénjarige gewassen als rijst, maïs en boonen, waarvan de producten minder zorgvuldige behandeling vragen en die niet aan spoedig bederf onderhevig zijn, verdienen daarom de voorkeur indien een verbeterde bedrijfsvorm ons in de gelegenheid stelt daarmede op de wereldmarkt met kans op succes te komen.

Enkele tientallen sinaasappelboomen op een perceel kunnen dan een niet te versmaden bijverdienste verschaffen.

$\mathrm{Nu}$ zal gezegd kunnen worden, dat voor aanschaffen van trekvee en werktuigen voor bovengenoemden bedrijfsvorm ook kapitaal vereischt wordt. Zeker is daar- 
voor, zelfs bij het kleinste bedrijf, eenig kapitaal noodig. Men moet in Suriname eindelijk eens leeren inzien, dat om eigen baas te zijn, vakkennis en kapitaal, hoe klein ook, onmisbaar zijn. Er zijn onder de kleine landbouwers genoeg menschen die zich, om te beginnen, een paar trekbeesten, een kleinen ploeg, egge en cultivator kunnen aanschaffen. Door de gunstiger omstandigheden waaronder deze zullen kunnen werken en meer produceeren, zullen zij een hooger dagloon kunnen betalen dan tot nu mogelijk was. Dat de kleine landbouwer gaarne een goed loon betaalt, als het hem zelf goed gaat, hebben wij gedurende den oorlog kunnen ervaren.

$\mathrm{Zij}$, die slechts met een houwer en een schop als gereedschap, zich als landbouwer gaan vestigen, zullen dit niet meer kunnen doen. Echter zullen ze veel gemakkelijker en op gunstiger voorwaarden dan nu op kleine bedrijven emplooi vinden en geleidelijk zal er zich een middenstand - de ruggegraat van elke gezonde maatschappij - ontwikkelen.

Met het inrichten van den polder beschikt men niet onmiddellijk over stompvrij land, dat voor bewerken met werktuigen geschikt is, maar geregeld over bevloeiingswater kunnende beschikken, zal men met handenarbeid reeds een grooter oppervlakte in cultuur kunnen nemen. $\mathrm{Na}$ enkele jaren, al naar gelang het bosch met hard of minder hard hout bezet was, zijn de stompen voldoende verrot om mechanische bewerking mogelijk te maken. Er wordt dan een nieuw stuk ontgonnen en uitbreiding vindt geleidelijk plaats.

In dit verband valt er op te wijzen, dat met betrekkelijk weinig kosten een boschterrein in enkele jaren in zoo goed als stompvrij land kan worden omgezet, indien wij bij de natuur in de leer gaan. Aan den rechteroever van de Commewijne-rivier, in Coronie, Nickerie vooral, maar ook op andere terreinen, komen groote uitgestrektheden boomvrij vruchtbaar land voor. Zoekt men de oorzaak, dan vindt men, dat het water op deze terreinen niet of moeilijk kan afvloeien, dat elk jaar gedurende een zekeren tijd het water dus vrij hoog blijft staan en boomgroei 
onmogelijk maakt. Meestal blijkt, dat er vroeger wel bosch gestaan heeft, maar dat de boomen later zijn doodgegaan. Op de suikerplantages worden de velden, die men eenige jaren wil laten braak liggen, dan ook onder water gezet om te voorkomen, dat er kapoewerie (secundair bosch) op groeit. Wordt dus een terrein ingepolderd en het water er op een zeker peil gehouden, dan sterven de boomen spoedig grondig af. De meerdere waarde van het land zal ruimschoots opwegen tegen het renteverlies gedurende enkele jaren.

De verwachting van den heer Van Drimmelen, dat de rijst voor Suriname kan worden, wat de tarwe is voor Canada en Argentinië, is voor verwezenlijking vatbaar, omdat alle voorwaarden voor goedkoope productie aanwezig zijn, nl. goedkoop land, overvloedig bevloeiingswater, terwijl in behoorlijk ingerichte polders mechanische bewerking van den grond en machinaal oogsten mogelijk worden; bovendien is, wat in Canada en Argentinië niet mogelijk blijkt, in Suriname wel bereikbaar nl. nog een volle oogst van een ander gewas over de geheele in cultuur zijnde oppervlakte.

De heer Van Drimmelen verwacht van een uitsluitend kapitalistischen bedrijfsvorm niet veel voor de toekomst. De heer Beck, die nieuwe bedrijfsvormen voor de bevolking bepleit, laat voorzichtigheidshalve in het midden of de toekomst van de kolonie van den grooten of van den kleinen landbouw afhangt. Mij dunkt dat beide noodig zijn en in de toekomst ook beide zich zullen handhaven. Het hier aangegeven systeem kan door beide in toepassing worden gebracht. De groote landbouw, over kapitaal kunnende beschikken, zal zich van intellectueele leiders der bedrijven kunnen verzekeren, die beter de vorderingen van techniek en wetenschap kunnen toepassen. Verbeteringen zullen in deze bedrijven sneller kunnen worden aangebracht. Kleinere bedrijven hebben het voordeel, dat scherper toezicht op den dagelijkschen gang van zaken gehouden wordt. De prikkel van het ei- 
genbelang is hier grooter. Ook hier zal van de vorderingen van techniek en wetenschap, al geschiedt dit in langzamer tempo, voordeel getrokken worden, zoowel door de voorlichting van het Landbouwdepartement als door afkijken van de groote ondernemingen.

De heer H. F. K. Douglas beschrijft in de Indische Mercuur van 30 Januari 1920, hoe in Noord-Amerika perceelen land voor den kleinen landbouw worden beschikbaar gesteld. Vaklieden vestigen de aandacht van het Gouvernement op een bepaalde streek, die geschikt is voor het doel. Deze streek wordt dan verkaveld, van wegen, afvoer- en irrigatiewerken voorzien. De risico van hen, die zich in dergelijke nederzettingen als landbouwer willen vestigen, wordt op die wijze heel wat kleiner, men heeft vertrouwen in de zaak. Zulke bebouw- en bewoonbaar gemaakte terreinen worden gemakkelijk aan den man gebracht, terwijl de uitkomsten met dergelijke ondernemingen over 't algemeen schitterend zijn. Het ligt daarom m.i. ook op den weg van het Gouvernement van een land als Suriname, dat tot ontwikkeling moet worden gebracht om in daarvoor gunstige streken groote polders aan te leggen, voorzien van wegen, afvoer- en irrigatiewerken en daar perceelen zoowel voor den grooten als voor den kleinen landbouw, tegen afbetaling op langen termijn, beschikbaar te stellen.

De groote ondernemingen behoeven dan geen kapitaal vast te leggen in polder- en irrigatie werken, terwijl het tijdverlies met aanleg dezer werken voor hen vermeden wordt.

De eerste polder met goede irrigatie, welke als proef zal moeten dienen voor den in dit artikel aanbevolen bedrijfsvorm, kan van meer bescheiden afmeting zijn. Daarna zullen ze zoo groot mogelijk moeten wezen, om het graafwerk machinaal te kunnen verrichten en de kosten per H. A. te verkleinen.

Paramaribo, April 1925. 